\title{
Research on Financing Efficiencies of Strategic Emerging Listed Companies by Six-Stage DEA Model
}

\author{
Qiong Wang ${ }^{1,2}$ and Cheng-xuan Geng ${ }^{1}$ \\ ${ }^{1}$ College of Economics and Management, Nanjing University of Aeronautics and Astronautics, Nanjing, Jiangsu 211106, China \\ ${ }^{2}$ School of Mathematics and Physics, Changzhou University, Changzhou, Jiangsu 213164, China \\ Correspondence should be addressed to Qiong Wang; wangqiong@cczu.edu.cn
}

Received 24 January 2017; Accepted 31 May 2017; Published 9 July 2017

Academic Editor: Nazrul Islam

Copyright (c) 2017 Qiong Wang and Cheng-xuan Geng. This is an open access article distributed under the Creative Commons Attribution License, which permits unrestricted use, distribution, and reproduction in any medium, provided the original work is properly cited.

\begin{abstract}
Accounting for the information of input slack variables, as well as the effects of external environment and stochastic factors, a six-stage DEA model was proposed based on four-stage DEA model. It was employed to assess the financing efficiencies of 689 strategic emerging listed companies in 2015. By isolating the environmental and stochastic factors, the final efficiencies can reflect the actual financing level of these companies. The empirical results show that most financing efficiencies are still at a low level relatively. The scales of these strategic emerging companies are the main constraint on their development. And the special technical level also has an impact on these efficiencies. In addition, the efficiency difference among provinces in China gives another support to environmental influence on the strategic emerging industry. Therefore, a strategic emerging company should pay attention to expanding its scale of production and heighten its special technical level and it should improve its financing efficiencies with the help of local government power.
\end{abstract}

\section{Introduction}

To speed up the cultivation and development of strategic emerging industries is not only a trend of global industrial restructuring, but also a major choice for the Chinese government to promote economic development model transformation and industrial structure upgrading. The development of strategic emerging industries has been upgraded to the national strategic level by our government. The capital is the core and artery of the strategic emerging industries' development. Under the new normal economic situation, mortgage financing and allocative efficiency of listed companies are seriously constrained by real financing ecosystem. Only by improving actual financing efficiencies of companies can the optimization function of resources' allocation of capital market be fully utilized. At the same time, we should optimize the structure of companies' capital and enhance their core competitiveness, to maximize the enterprise value and promote the sustainable development of the whole industry. Therefore, this paper intends to research actual financing efficiencies of strategic emerging companies. It may provide a more profound theoretical interpretation and more fully empirical evidence for the strategic emerging industries.

The research on financing theory and efficiency theory of foreign scholars emerged in the 1950s. Companies' financing in western countries is often efficient because of their mature property system and property rights' system. Therefore, most literature focuses on allocation efficiency of financial structure or market, while there is little literature about financing efficiency. Guney et al. [1] studied the relationship between product market competition and financial structure of listed companies based on a series of static and dynamic data. By theoretical models, Hovakimian et al. [2] found that when determining the financial structure, companies should choose debt financing to support the current business and choose equity financing to ensure the need to grow, so as to ensure their financing efficiency. Gomariz and Ballesta [3] studied financing efficiencies on the sample of Spanish listed companies during 1998-2008. The results showed that improving financial leverage can help to reduce excessive investment, and improving debt maturity structure 
can help to raise financing efficiency, thus reducing excessive investment and insufficient capital investment.

Since the conception of financing efficiency was proposed by Zeng (1993) [4], many scholars in China have further researched on financing efficiency. The financing efficiency of enterprises is to create the financing capacity of the enterprises value. Only if compared with other companies and with its past, a company will know its financing efficiency. Longterm debt financing had little influence on small and medium enterprises using the gray correlation analysis method, while equity financing efficiencies of majority listed companies in China were inefficient [5]. Cheng et al. [6] researched relative efficiencies of listed companies in strategic emerging industries during 2005-2011 using BCC model. The results showed that most efficiencies of listed companies are inefficient. Huang et al. [7] selected Beijing high-tech industry data during 1995-2009 and measured technical efficiencies with SFA and three-stage DEA model. Based on the threestage DEA model, Shen and Zhang [8] evaluated financing efficiencies of new OTC enterprises in 2015, by isolating the environmental factors and adjusting input values. The final measurement of efficiencies can accurately reflect the actual efficiencies of these companies. Additionally, Cao and Geng [9] studied financing efficiencies of energy saving and environmental protection companies during 2012-2014 by using four-stage DEA model.

Based on relevant literatures, compared with other methods, the DEA method is relatively objective to determine weights of inputs and outputs [10]. But, to date, financing efficiency is mainly based on a low-stage DEA model. In onestage DEA model, environmental variables are considered as inputs or outputs. But it is required to identify the influential direction of environmental variables on efficiencies in advance. In two-stage DEA model, introducing Tobit regression model enables it to explain the significance of environmental variables on efficiencies. However, the efficiency values cannot be adjusted according to the regression results because this model does not make full use of the slack variable information. Then Stochastic Frontier Analysis (SFA) is employed to slack variables to adjust inputs or outputs in three-stage DEA model proposed by Fried. But the parameter estimations obtained are not consistent due to dependent variable truncation in SFA. Consequently, by replacing SFA regression in three-stage DEA model with Tobit regression, parameter estimates in four-stage DEA model are consistent. However, this model cannot eliminate the stochastic effect.

Therefore, this paper will present a new six-stage DEA model by introducing Tobit and SFA regression, which isolates both environmental factors and stochastic factors to evaluate actual efficiencies. This model is applied for evaluating financing efficiencies of listed strategic emerging companies in China. This model can filter the effect of external environmental and stochastic factors to measure pure financing efficiencies of listed companies operating in the same ecological environment along with the same bad fortune. Therefore, initial inputs are adjusted for the external environmental effects and uncontrollable fortunes. Three environmental variables are used to judge the direction of impact on financing efficiencies. These include differences in financial environment, technological innovation, and market demand. The empirical analysis offers initial DEA efficiency estimates without these effects in a second stage. Later, Tobit regression is applied to find out those negative environmental variables. In the fourth stage, the estimates in SFA regression are obtained and then employed in the adjustment of inputs. Finally, DEA model is used again with adjusted inputs and initial outputs to obtain the final company efficiencies. The results show the importance and necessity of making such adjustments to assess this financing performance of companies. This adjustment makes most financing efficiencies of companies decreased as well as making the efficiency ranking declined.

The next section provides more details of the methodology followed by the explanations of data sources, variable selections, and empirical analyzing. The final section is a conclusion.

\section{Methodology}

Assessing efficiencies will begin with DEA model along with BCC-DEA model (variable returns to scale, VRS) which Banker et al. proposed in 1984 [11]. Then the analysis combined with Tobit and SFA model will proceed to consider the effects of environmental factors on efficiencies obtained from the DEA model. The empirical focus will be on the efficiencies of company's finance. The outputs will be gross revenue and net profit. Given different financing channels, choosing an input-oriented DEA model to assess efficiencies is appropriate. In view of the maximization of profits, companies are asked to produce the same or more outputs with less inputs. Therefore, BCC-DEA model with variable returns to scale (VRS) is employed in the paper.

2.1. Stage 1 and Stage 2: Index Selection and DEA Model. We begin with each of $n$ companies with $m$ inputs and $q$ outputs. Ideally, company management has thorough control over these inputs which impact all outputs. For the jth decision unit, the corresponding standard input and output data are, respectively, noted as follows:

$$
\begin{aligned}
& x_{j}=\left(x_{1 j}, x_{2 j}, \ldots, x_{m j}\right)^{T}, \\
& y_{j}=\left(y_{1 j}, y_{2 j}, \ldots, y_{q j}\right)^{T}, \\
& \quad j=1,2, \ldots, n .
\end{aligned}
$$

By standard notation [12], the linear programming in the first stage under consideration is as follows:

$\min \theta$

$$
\begin{gathered}
\text { subject to: } \quad \theta x_{i 0} \geq \sum_{j=1}^{n} \lambda_{j} x_{i j} \\
\sum_{j=1}^{n} \lambda_{j} y_{r j} \geq y_{0}
\end{gathered}
$$




$$
\begin{aligned}
& \sum_{j=1}^{n} \lambda_{j}=1 \\
& \lambda_{j} \geq 0 \\
& i=1,2, \ldots, m ; \\
& j=1,2, \ldots, n ; \\
& r=1,2, \ldots, q .
\end{aligned}
$$

$\theta$ are financial efficiencies and $\lambda$ are weights of inputs $(x)$ or outputs $(y)$ for companies. The number of inputs $(x)$ is five in total, described in more detail in the following section. The BCC-DEA model results in assessing the operating performance of each company such that $0 \leq \theta \leq 1$. Companies are evaluated as efficient units when $\theta=1$. These efficient companies rely on the efficient production frontier and envelop those inefficient companies.

The efficiency estimates obtained in BCC-DEA model include three effects: (1) differences in the allocation of financing resources in management decisions; (2) differences in the external environments in which companies are operating; (3) stochastic events that impose good or bad fortune to companies. Therefore, the efficiency estimates obtained in this stage did not take into account the external environmental effects. Then the companies operating in an unfriendly environment were unable to compare with the companies operating in a relatively friendly environment.

Consequently, modified efficiencies will be equal for those companies with the same managerial competencies, if inputs could be adjusted to place companies with additional resources in unfriendly provinces with those in a nondifferentiated environment. After adjusting all the inputs, companies that obtain lower efficiencies could no longer be attributed to the external environment relative to other companies.

Since this stage of the BCC-DEA model cannot differentiate the initial efficiencies which are due to the internal or external factors, the following stages are required.

2.2. Stage 3: Tobit Regression. Influenced by external environments, the efficiencies obtained from the above BCC model cannot accurately reflect the real status of companies. A fourstage DEA model proposed by Fried et al. [13] accounts for the external environmental effects, to isolate the inefficiency performance due to the management competency. But the lowest efficiency value is 0 ; that is, dependent variables are truncated on the left. Tobit regression is employed in this stage, in which dependent variables are truncated. Consequently, Tobit model is established as follows:

$$
\begin{array}{r}
\theta_{j}=\beta_{0}+\sum_{k=1}^{K} \beta_{k} e_{k j}+\varepsilon_{j}, \\
k=1,2, \ldots, K ; j=1,2, \ldots, n .
\end{array}
$$

The dependent variables $\theta$ are efficiencies to be estimated, and the independent variable $e_{k j}$ represents the $k$ th environmental variable of $\mathrm{DMU}_{j} \cdot \beta_{k}(k=0,1, \ldots, K)$ are coefficients to be estimated. $\varepsilon \sim N\left(0, \sigma^{2}\right)$ represent the independent residual terms. $K$ is the number of environmental variables.

Tobit model is applied to identify the direction of environmental factors impact on the efficiencies to obtain pure management efficiencies. When a regression coefficient is positive and statistically significant, increasing the corresponding external environmental variable helps to improve the efficiencies. In other words, the changing direction of this factor is the same with the efficiencies. Then this factor is called a negative environmental variable $e^{-}$. Otherwise, it is called a positive environmental variable noted by $e^{+}$.

2.3. Stage 4: SFA Regression. The stochastic frontier approach (SFA) is applied to improve the disadvantages of the BCC model which is difficult in dealing with the external environment and stochastic disturbance factors. The total slack variables of the initial inputs are selected as the dependent variables and the negative environmental variables as the explanatory variables in the stochastic frontier cost equation. The specific cost equation is as follows:

$$
\begin{aligned}
s_{i j}^{-}=\sum_{k=1}^{K_{1}} \beta_{k} e_{k j}^{-}+v_{i j}+u_{i j} & \\
& (i=1,2, \ldots, m ; j=1,2, \ldots, n),
\end{aligned}
$$

where $v_{i j} \sim N\left(0, \sigma_{v}^{2}\right)$ represent the random error terms beyond the control of $\mathrm{DMU}_{j}$ and $u_{i j} \sim N^{+}\left(\mu, \sigma_{u}^{2}\right)$ represent the inefficient items which $\mathrm{DMU}_{j}$ can control but are not yet efficient. The relationship between $v_{i j}$ and $u_{i j}$ is independent and irrelevant. $K_{1}$ is the number of negative environment variables.

Compared with nonparametric methods, the main advantages of SFA method are distinguishing stochastic factors from technical inefficiencies and being tested econometrically on the regression model. In essential, the explained variable in this model will be discomposed to three parts, cost function, stochastic factors, and technical inefficiency. Through the adjustment on initial inputs in view of the external environmental factors uncontrolled and stochastic error as well as deeper information mining, an objective and comprehensive evaluation will be obtained.

2.4. Stage 5 and Stage 6: Inputs Adjustment and DEA Model. Using the maximum fitting value of each input variable and the stochastic error term, the initial inputs are adjusted. The formula is as follows:

$$
\begin{array}{r}
x_{i j}^{\text {adj }}=x_{i j}+\left[\max _{j}\left\{\widehat{s}_{i j}^{-}\right\}-\widehat{s}_{i j}^{-}\right]+\left[\max _{j}\left\{\widehat{v}_{i j}\right\}-\widehat{v}_{i j}\right], \\
(i=1,2, \ldots, m ; j=1,2, \ldots, n) .
\end{array}
$$

$x_{i j}^{\text {adj }}$ is the adjusted $i$ th input of DMU ${ }_{j}$ and $\widehat{s}_{i j}^{-}$is the slack fitting value from the SFA regression. The random error terms $v_{i}$ are estimated by

$$
\widehat{E}\left[v_{i} \mid v_{i}+u_{i}\right]=s_{i}-z_{i} \widehat{\beta}-\widehat{E}\left[u_{i} \mid v_{i}+u_{i}\right] .
$$


TABLE 1: Input, output, and environmental variables.

\begin{tabular}{|c|c|c|c|}
\hline First order & Second order & Third order & Notation \\
\hline \multirow{5}{*}{ Input } & \multirow{2}{*}{ Internal financing } & Surplus reserve & Input1 \\
\hline & & Undistributed profits & Input2 \\
\hline & Debt financing & Noncurrent liabilities & Input3 \\
\hline & \multirow{2}{*}{ Equity financing } & Paid-up capital & Input4 \\
\hline & & Capital surplus & Input5 \\
\hline \multirow{2}{*}{ Output } & \multirow{2}{*}{ Revenue } & Gross revenue & Output1 \\
\hline & & Net profit & Output2 \\
\hline \multirow{3}{*}{ Environment } & Financial environment & Local RMB loans balance of financial institutions at year end & $E 1$ \\
\hline & Technological innovation & Local cumulative number of patents granted in the past three years & $E 2$ \\
\hline & Market demand & Current gross domestic product & E3 \\
\hline
\end{tabular}

After the above adjustment, $x_{i j}^{\text {adj }}$ would not only punish those DMUs with better performance and higher efficiency due to friendly external environment, but also filter the stochastic factors of DMUs. In other words, all DMUs have the same luck and are in the most severe external environment.

The final stage is once again the application of the BCCDEA model but with the inputs adjusted by (5) and initial outputs to recalculate efficiencies. Due to excluding the effect of the external environment and stochastic factors, the efficiency estimates obtained can accurately reflect pure efficiencies of each DMU.

\section{Data}

3.1. Sources. This paper selected seven strategic emerging industries as the initial sample from Shanghai and Shenzhen Stock mark in 2015. The initial sample includes new materials, new energy, energy-saving environmental protection, new energy automobile, and high-end equipment manufacturing industry, as well as emerging information technology industry. To keep the consistency of the data sample, the sample followed the following criteria: (1) excluding ST stocks and delisted stocks, because these companies' financial data are abnormal; (2) excluding the listed companies lack of related data; (3) eliminating the effects of extreme values, by the Winsorize procession at $1 \%$ level. Finally we selected 689 listed companies as the final sample. All data are drawn from CSMAR database and China's statistical yearbook.

3.2. Variables. When studying the financing efficiencies, we consider two kinds of financing channels including internal financing and external financing. The external financing involves debt financing and equity financing. By relevant literature, this paper selected "surplus reserve" and "undistributed profits" as internal financing inputs to measure internal investment intensity, "noncurrent liabilities" as debt financing input, and "paid-up capital" and "capital surplus" as equity financing inputs to measure exogenous investment intensity. The final performance on financing efficiency of listed companies includes the market performance and management level. Then "gross revenue" and "net profit" are selected as outputs to measure the revenue of a company. The principle of selecting these environment variables is that these environmental variables have some effects on the outputs but are uncontrolled by the companies. RMB loans balance of financial institutions at year end in local region represents the financial supporting on the development of strategic emerging companies, the number of patents in local region over the past three years represents the influence of local innovation environment on the development of strategic emerging companies, and current GDP represents local market demand [14]. These variables reflect the different aspects of the external environment in which companies are operating. A summary of the variables is presented in Table 1.

\section{Results}

4.1. First-Stage Descriptive Analysis. The descriptive analysis of variables is shown in Table 2. Each variable differs greatly among companies. The difference between the maximum and minimum of the three environmental variables is more than 70 times. For example, the maximum of $E 1$ is 250290 , but the minimum of $E 1$ is only 198 . Therefore, it is important to eliminate these environmental effects. DEA model requires values of inputs and outputs should be all positive, but the actual data may exist as negative such as undistributed profits and capital surplus. Therefore, all data are processed to be positive by adding some constants [15].

According to the DEA index selection principle, the input variables should have positive effects on the company's expected outputs. In other words, output must not be reduced by increasing inputs. Person correlations were examined and specific results are presented in Table 3.

From Table 3, all the correlation coefficients between the inputs and outputs are positive, and most of them are significant at the $1 \%$ significant level by two-tailed test. This indicates that there is indeed a significant positive correlation between inputs and outputs. Besides, the number of DMUs is 689 , far more than the number of all input and output variables. This conforms to the principle of index selection. Consequently, these variables are appropriate for assessing financing efficiencies by DEA model.

4.2. Second-Stage BCC-DEA. Based on the BCC-DEA model, we can obtain the financing efficiencies of companies. The results are shown in Table 4 and Figure 1. 
TABLE 2: Description of input and output variables.

\begin{tabular}{lccccc}
\hline Variable & Mean & Median & Max & Min & St. deviation \\
\hline Input 1 & 342176032.99 & 75475899.74 & 26728261764.70 & 0.00 & 1526397009.85 \\
Input2 & 1685223371.08 & 505705069.07 & 86397638086.22 & -7570201787.61 & 5248238675.90 \\
Input3 & 2006965403.44 & 62440000.00 & 164956374000.00 & 0.00 & 10795776276.32 \\
Input4 & 1126773128.15 & 560000000.00 & 27288758000.00 & 39479848.00 & 2365547667.30 \\
Input5 & 1590603835.70 & 805417338.16 & 38939769815.73 & -464961817.04 & 3214993026.70 \\
Output1 & 91726.24 & 72818.00 & 200032.00 & 146.00 & 70.00 \\
Output2 & 19835.38 & 17601.00 & 36015.00 & 198.00 & 13201.33 \\
E1 & 118262.81 & 94031.00 & 250290.00 & 465.00 & 92290.22 \\
E2 & 304144.22 & 231363.00 & 689967.00 & 620.80 & 245208.71 \\
E3 & 35627.50 & 27367.04 & 67792.24 & & 20117.52 \\
\hline
\end{tabular}

TABLE 3: Correlation between the input and output variables.

\begin{tabular}{lccccc}
\hline Variable & Input1 & Input2 & Input3 & Input4 & Input5 \\
\hline \multirow{2}{*}{ Output1 } & $0.6725^{* * *}$ & $0.8636^{* * *}$ & $0.3738^{* * *}$ & $0.6398^{* * *}$ & $0.7530^{* * *}$ \\
& 0.0000 & 0.0000 & 0.0000 & 0.0000 & 0.000 \\
Output2 & $0.7565^{* * *}$ & $0.9098^{* * *}$ & 0.4060 & $0.6020^{* * *}$ & $0.6946^{* * *}$ \\
& 0.000 & 0.000 & 0.439 & 0.000 & 0.000 \\
\hline
\end{tabular}

Note. ${ }^{* * *} p<0.01$.

TABLE 4: Financing efficiencies with unadjusted inputs.

\begin{tabular}{lcccccccccc}
\hline & Mean & Median & Min & Max & Std. & Efficient, \# & Efficient, \% & Constant & Decreasing & Increasing \\
\hline CRS & 0.821 & 0.842 & 0.213 & 1 & 0.114 & 41 & $5.95 \%$ & & & \\
VRS & 0.867 & 0.892 & 0.220 & 1 & 0.114 & 65 & $9.43 \%$ & & \\
SC & 0.947 & 0.951 & 0.468 & 1 & 0.047 & 43 & $6.24 \%$ & $6.24 \%$ & $8.13 \%$ & $85.63 \%$ \\
\hline
\end{tabular}

TABLE 5: Tobit regression of financing efficiencies.

\begin{tabular}{lcccc}
\hline Variable & Coefficient & Std. error & $z$-statistic & Prob. \\
\hline$E 1$ & $2.73 E-09^{* * *}$ & $1.27 E-10$ & 21.4193 & 0.0000 \\
$E 2$ & $-2.05 E-06$ & $1.11 E-07$ & -1.0811 & 0.1400 \\
$E 3$ & $6.85 E-06^{* * *}$ & $1.10 E-06$ & 6.2529 & 0.0000 \\
\hline
\end{tabular}

Note. ${ }^{* * *} p<0.01$.

From the financing efficiency estimates, it can be observed that, for 689 companies in China, the mean of overall financing efficiencies (CRS), pure technical efficiencies (VRS), and scale efficiencies (SC) is $0.821,0.867$, and 0.947, respectively. It indicates that if operating effectively, each company may maintain these outputs with fewer inputs. Specifically, most companies had capital redundancy and made no full use of funds after financing. It follows that still there is room to enhance the overall financing efficiencies of strategic emerging industry. Moreover, there is a stark difference among financing efficiencies. For example, the minimum financing efficiency is surprisingly low at 0.213 under CRS. This indicates that about $78.7 \%$ of capital financing is inefficient. $85.63 \%$ of companies are in the stage of increasing scale return to scale. Hence, these companies can increase their inputs to obtain their outputs in the equal proportion. Only $5.95 \%$ companies with $\theta=1$ are efficient. The linear combinations with their inputs and outputs constitute a frontier of financing efficiencies. In summary, the financing efficiencies of strategic emerging industry in China remain to be improved in the future.

4.3. Third-Stage Tobit. The effects of environmental variables on efficiencies can be determined by Tobit model. Specific results in Tobit model are shown in Table 5. The coefficients of environmental variables $E 1$ and $E 3$ are positive and highly significant, indicating that the greater the variables $E 1$ and $E 3$, the greater the financing efficiencies of companies. Therefore, they are called negative environmental variables. But the coefficient of environmental variable $E 2$ is negative and not significant. The changing direction of this environmental variable E2 is different from financing efficiencies. According to the principle of the same direction, this environmental variable $E 2$ is called a positive environmental variable.

4.4. Fourth-Stage SFA and Fifth-Stage Adjustments. Because input-oriented BCC model is applied in the paper, we need to consider just the adjustment of the two negative variables 
TABLE 6: SFA regression of input slacks for environmental variables.

\begin{tabular}{|c|c|c|c|c|c|}
\hline & Input1 slack & Input2 slack & Input3 slack & Input4 slack & Input5 slack \\
\hline \multirow{2}{*}{ Constant } & $0.981^{* * *}$ & -0.222 & $5.765^{* * *}$ & $-20.077^{* * *}$ & $0.020^{* * *}$ \\
\hline & $(0.584)$ & $(0.199)$ & $(0.980)$ & $(0.999)$ & $(0.039)$ \\
\hline \multirow{2}{*}{$E 1$} & $-0.108^{* * *}$ & $0.012^{* *}$ & $-0.706^{* * *}$ & $1.709^{* * *}$ & $-0.002^{* * *}$ \\
\hline & $(0.549)$ & $(0.011)$ & $(0.217)$ & $(0.464)$ & $(0.005)$ \\
\hline \multirow{2}{*}{ E3 } & $0.105^{* * *}$ & $-0.002^{*}$ & $0.740^{* * *}$ & -1.387 & $0.001^{* * *}$ \\
\hline & $(0.710)$ & $(0.002)$ & $(0.423)$ & $(0.887)$ & $(0.005)$ \\
\hline \multirow{2}{*}{ Sigma2 } & $192.158^{* * *}$ & $1.064^{* * *}$ & $201.596^{* * *}$ & $212.772^{* * *}$ & $239.869^{* * *}$ \\
\hline & $(0.983)$ & $(0.081)$ & $(0.999)$ & $(0.999)$ & $(1.023)$ \\
\hline \multirow{2}{*}{ Gamma } & $0.999^{* * *}$ & $0.989^{* * *}$ & $1.000^{* * *}$ & $0.999^{* * *}$ & $0.999^{* * *}$ \\
\hline & $(0.000)$ & $(0.000)$ & $(0.000)$ & $(0.000)$ & $(0.000)$ \\
\hline Log likelihood & $-2253.260^{* * *}$ & $-497.218^{* * *}$ & $-2186.154^{* * *}$ & $-2236.313^{* * *}$ & $-2281.918^{* * *}$ \\
\hline $\operatorname{Max} s_{i}$ & 1.075 & 67027262.662 & 593691273.125 & 295571107.388 & 432983422.494 \\
\hline $\operatorname{Max} v_{i}$ & 18.8710 & 5.6075 & 5.4956 & 4.0589 & 2.4884 \\
\hline
\end{tabular}

Note. ${ }^{*} p<0.1,{ }^{* *} p<0.05$, and ${ }^{* * *} p<0.01$, and the values in brackets are standard errors of estimates.

TABLE 7: Financial efficiencies with adjusted inputs.

\begin{tabular}{lcccccccccc}
\hline & Mean & Median & Min & Max & Std. & Efficient, \# & Efficient, $\%$ & Constant & Decreasing & Increasing \\
\hline CRS & 0.829 & 0.844 & 0.218 & 1 & 0.118 & 50 & $7.26 \%$ & & & \\
VRS & 0.870 & 0.894 & 0.2239 & 1 & 0.113 & 72 & $10.45 \%$ & & \\
SC & 0.953 & 0.959 & 0.4718 & 1 & 0.047 & 50 & $7.26 \%$ & 0 & $19.74 \%$ \\
\hline
\end{tabular}
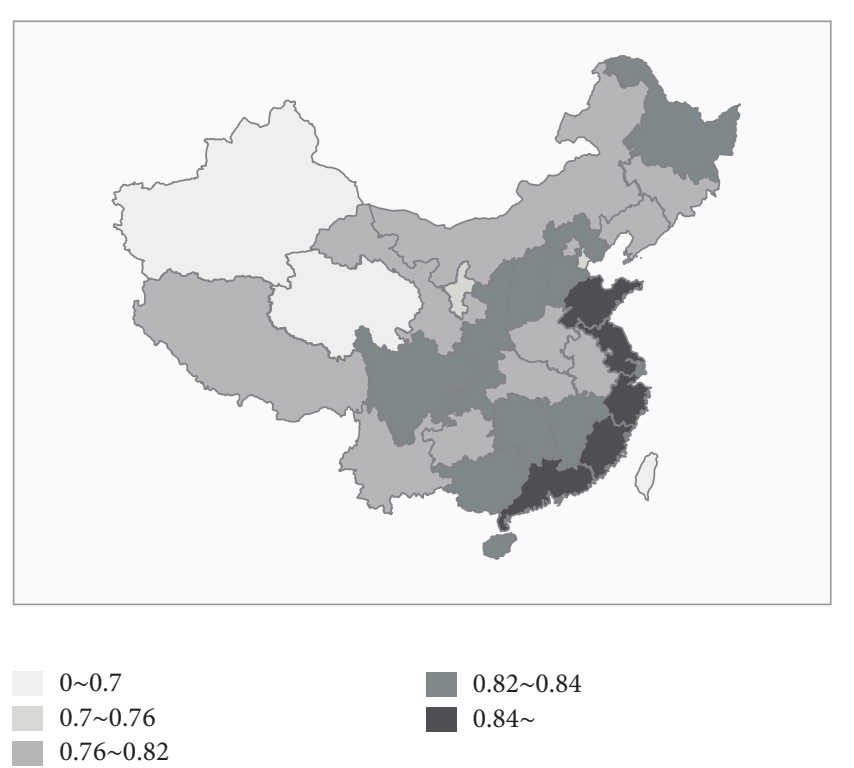

FIGURE 1: Financing efficiencies in BCC-DEA model.

on input slacks. SFA regression with variables $E 1$ and $E 3$ is applied to all input slacks. In SFA regression, the estimates of inefficiency components obey the law of a half-normal distribution. For the estimates of five slack variables, managerial inefficiency is significant in determining input redundancies. Actually, the gamma estimates of other slacks apart from noncurrent liabilities are very close to 1 , which means these input slacks are mainly due to management. These results also show that two environmental variables affect significantly input slacks. But, in noncurrent liabilities slack, the gamma is weaker but highly significant. It indicates that stochastic noise carries relatively greater impact. The results of SFA regression are shown in Table 6. The coefficient for variable $E 1$ is consistently negative in input1, input 3 , and input 5 slacks, then suggesting that the financing efficiencies are in line with a favorable or friendly operating environment. The better this environmental condition is, the less the redundancies of input1, input3, and input 5 are. In the remaining slacks, the effects of $E 1$ are positive and significant. The environmental variable E3 is just the opposite. But all the gammas and the likelihood ratios are statistically significant which support the frontier specification.

4.5. Final-Stage BCC-DEA. According to the results of SFA regression, the maximums of input slacks obtained from the SFA regression are due to the environmental effects, while the means are due to statistical noise. The adjusted inputs of the final stage are computed by (5). The final efficiencies are recalculated with adjusted inputs and initial outputs to eliminate external environmental effects. In addition, there is the same luck at work as indicated by statistical noise. The results are given in Table 7.

Compared to the previous efficiencies, the efficiencies of all companies are improved with the adjustments for external environmental factors and good or bad luck. As far as CRS and VRS are concerned, the mean efficiency is over $0.8 \%$ or $0.3 \%$ increase over the first stage. The mean efficiency of VRS increased from 0.867 to 0.870 . The median VRS efficiency with the adjusted inputs is 0.894 , an increase of $0.2 \%$ points. There is a little change in the minimum of company efficiencies under CRS (from 0.213 to 0.218 ) and 
TABLE 8: Efficiency ranking changes.

\begin{tabular}{lccccc}
\hline$E 1$ & $N$ & $\Delta>0$ & $\Delta=0$ & $\Delta<0$ & Mean $\Delta$ \\
\hline$E 1 \geq 450,000,000$ & 234 & 72 & 21 & 141 & -18.56 \\
$380,000,000 \leq E 1<450,000,000$ & 185 & 114 & 26 & 45 & 56.75 \\
$E 1<380,000,000$ & 270 & 57 & 34 & 81 & -21.30 \\
\hline Total & 689 & 243 & 365 & 0.51 \\
\hline
\end{tabular}

VRS (from 0.220 to 0.224 ). Although these improvements of company financing efficiencies are not dramatic, it must be noted that the number of efficient companies under CRS is more than a $22.0 \%$ increase (from 41 to 50 ). The improvement of company efficiencies supports that the financing efficiencies with which companies can produce revenue are affected by market demand and also financial environment. For SC, nearly $80.26 \%$ of companies are in the stage of increasing returns to scale. This indicates that these companies can expand the scale to increase revenue.

The rankings on financing efficiencies can provide a new insight into the adjustment effects with different operating environments. The rank correlation between the efficiency rankings with initial inputs and the rankings with adjusted inputs is 0.92. Using the CRS estimates, the mean on the financing efficiency rank change is 0.51 . But the total effects of the above adjustment resulted in 243 companies improving their ranking, 81 companies maintaining their ranking positon, and 365 companies slipping down the list.

Obviously, it is inappropriate to ascribe all the changes of company ranking that are caused by adjusting local financial environment. Moreover, there are other environmental factors and good or bad fortune at work. Unfortunately, marginal effect analysis is impractical for all possible environmental combination involved. From financial environmental perspective, the comparison between the financing efficiency rankings with the initial inputs and with the adjusted inputs was carried out.

In order to uncover how the adjustment to the initial inputs can lead to the change of efficiency ranking for financial environmental effect, this environmental variable $E 1$ is divided into three classes. The specific results are shown with a decomposition of changes in Table 8.72 of 234 companies in the friendly financial environments improved their rankings by adjusting the initial inputs. Rank improvements occurred for 57 of 270 companies in the unfriendly financial environments. But there are 114 of 185 companies in the second group of financial environment. Another comparison is presented in the sixth column of Table 8 . The mean efficiency ranking change in the friendly financial environmental group (18.56) was less than that (21.30) in the unfriendly financial environmental group. In summary, the central regions with the middle range of $E 1$ will experience a great progress if the environment changes to be friendly. In contrast, other regions will witness less progress.

\section{Conclusions}

The proposed model divides environmental variables into two categories: positive and negative variables. It avoids identifying the influence direction of environmental variables on efficiencies in advance. Moreover, this model combined with Tobit and SFA regression can eliminate the environmental and stochastic effect by using the information of slack variables. Thus, the final efficiencies obtained from the proposed model are pure financing efficiencies to reflect the actual financing level of these companies.

Changes in the operating environment facing the strategic emerging companies are well underway. A focus on financing environments helps to evaluate company financing performance. In order to research financing efficiencies, financing efficiencies from BCC-DEA model are compared with those from the proposed model eliminating both environmental and stochastic factors in this paper. The nonparametric efficiencies in the final stage rely on Tobit and SFA regression which parametrically determined the adjustments to the inputs. Therefore, the modified efficiencies are based on the same fortune and external environmental factors that the company decision-makers cannot control. The latter are determined by financial and market environment and measured as the differences in the local RMB loans balance of financial institutions as well as gross domestic product.

The results indicate that the mean increment of company efficiencies is $0.8 \%$ points, from $82.1 \%$ in BCC-DEA model to $82.9 \%$ in the six-stage DEA model by eliminating environmental and stochastic effects. Although current company efficiency improvement is not dramatic, the weak difference for company efficiencies does not reduce the necessity and importance of the adjustment process. A significant difference resulting from the adjustment was found to be the increase in the number of efficient companies from 41 to 50 , or a nearly $22.0 \%$ increase. Thus, the combined evidence supports the positive shift of efficiency distribution as well as the change of company efficiency ranking. Moreover, the latter would be more important if any company performance takes efficiency differences in financial ecological environment into account.

From the above discussions, the financing efficiencies of strategic emerging industry in China still remain to be improved. On the one hand, most strategic emerging companies should focus on expanding their scales of production and encourage technological innovation. They should gradually optimize their governance structures and develop the ability of financing technological progress. On the other hand, we should maintain and strengthen the financial system of financial support and resort to local government power to improve the financing efficiencies.

\section{Conflicts of Interest}

The authors declare no conflicts of interest. 


\section{Authors' Contributions}

Qiong Wang and Cheng-xuan Geng conceived the experiments. Qiong Wang performed the experiments and analyzed the data. All authors wrote the paper.

\section{Acknowledgments}

This research is supported by National Social Science Foundation of China (15BGL056), Key Projects from Philosophy and Social Science Fund of Universities in Jiangsu Province (2015ZDIXM008), and Fundamental Research Funds for Central Universities (NP2015302).

\section{References}

[1] Y. Guney, L. Li, and R. Fairchild, "The relationship between product market competition and capital structure in Chinese listed firms," International Review of Financial Analysis, vol. 20, no. 1, pp. 41-51, 2011.

[2] A. Hovakimian, T. Opler, and S. Titman, "The debt-equity choice," Journal of Financial and Quantitative Analysis, vol. 36, no. 1, pp. 1-24, 2001.

[3] M. F. C. Gomariz and J. P. S. Ballesta, "Financial reporting quality, debt maturity and investment efficiency," Journal of Banking and Finance, vol. 40, no. 1, pp. 494-506, 2014.

[4] K.-L. Zeng, "What about direct financing and indirect financing," Journal of Financial Research, vol. 10, pp. 7-11, 1993.

[5] L.-C. Liu, G.-F. Feng, D.-H. Zhang, and H.-X. Mao, "Efficiency evaluation on equity finance of listed companies on basis of DEA," Systems Engineering, vol. 22, no. 1, pp. 55-59, 2004.

[6] G.-S. Cheng, Y. Zhang, and M.-J. Rui, "On the relative efficiency between state-owned and private enterprises in the development of strategic emerging industries: an empirical analysis based on the data of listed companies from 2005 to 2011," Contemporary Finance and Economics, vol. 10, pp. 96-105, 2013.

[7] L.-C. Huang, X.-M. Zhang, F.-F. Wu, and H. Miao, "Empirical study on the technical efficiency of Beijing high-tech industry based on three-stage DEA Model," in Proceedings of the Technology Management for Emerging Technologies, pp. 3352-3357, IEEE, New York, 2012.

[8] C. Shen and L.-M. Zhang, "A research on financing efficiency of SMEs in NEEQ market: private placement based on three stage DEA model," Journal of Audit and Economics, vol. 3, pp. 78-86, 2017.

[9] Y. Cao and C.-X. Geng, "Research on financing efficiency of energy saving and environmental protection companiesbased on four stage dea-malmquist model," Environmental Science and Management, vol. 41, no. 3, pp. 6-10, 2016.

[10] S.-Y. Ye and H. Wang, "Research on decision making units' homogeneity of multiply-stage DEA," Statistics and Information Forum, vol. 27, no. 2, pp. 15-21, 2012.

[11] R. D. Banker, A. Charnes, and W. W. Cooper, "Some models for estimating technical and scale inefficiencies in data envelopment analysis," Management Science, vol. 30, no. 9, pp. 10781092, 1984.

[12] W. D. Cook, K. Tone, and J. Zhu, "Data envelopment analysis: prior to choosing a model," Omega, vol. 44, no. 2, pp. 1-4, 2014.

[13] H. O. Fried, C. A. K. Lovell, S. S. Schmidt, and S. Yaisawarng, "Accounting for environmental effects and statistical noise in data envelopment analysis," Journal of Productivity Analysis, vol. 17, no. 1-2, pp. 157-174, 2002.
[14] S. Zeng, M. Hu, and B. Su, "Research on investment efficiency and policy recommendations for the culture industry of China based on a three-stage DEA," Sustainability, vol. 8, no. 4, article no. 324, pp. 1-15, 2016.

[15] Z.-X. Ma and H. Tang, "On the invariant properties of DEA method under the data transformation," Journal of Systems Engineering, vol. 14, no. 2, pp. 129-134, 1999. 


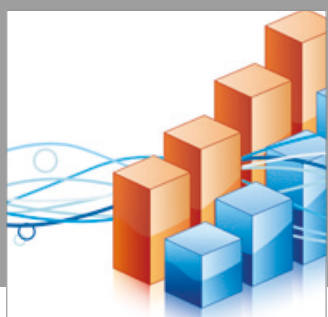

Advances in

Operations Research

vatersals

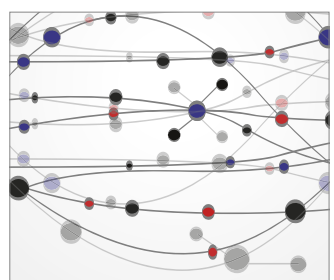

\section{The Scientific} World Journal
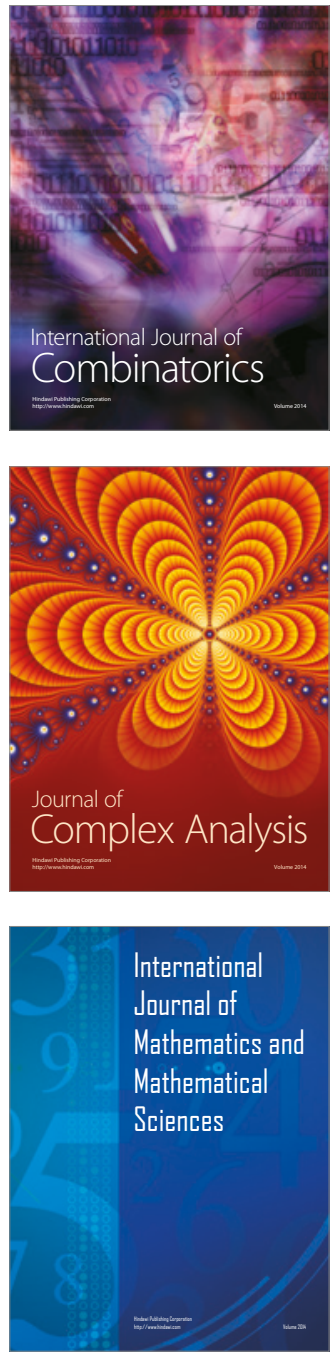
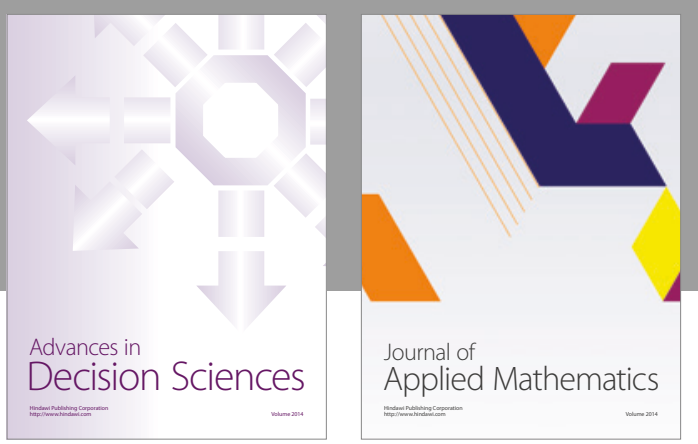

Algebra

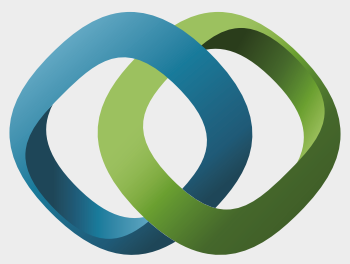

\section{Hindawi}

Submit your manuscripts at

https://www.hindawi.com
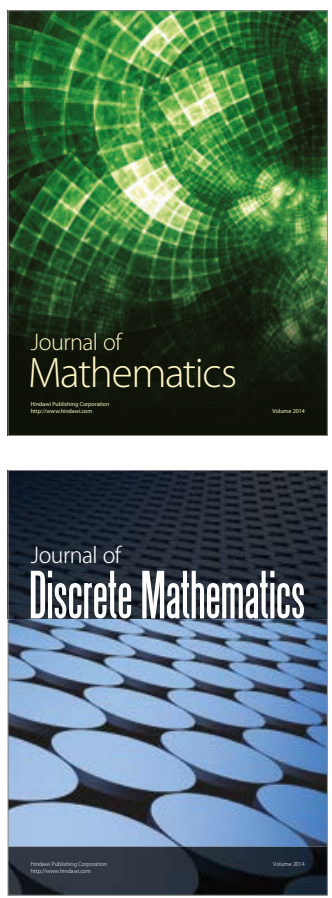

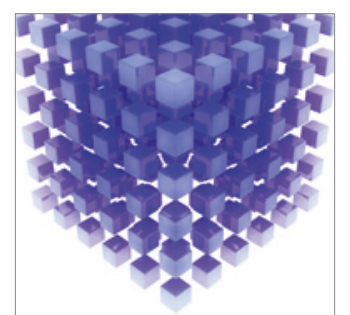

Mathematical Problems in Engineering
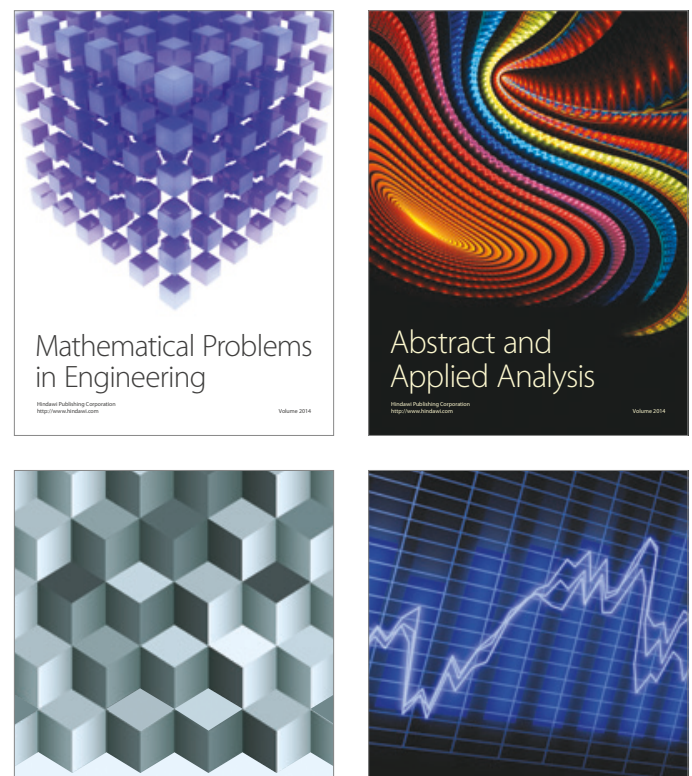

Journal of

Function Spaces

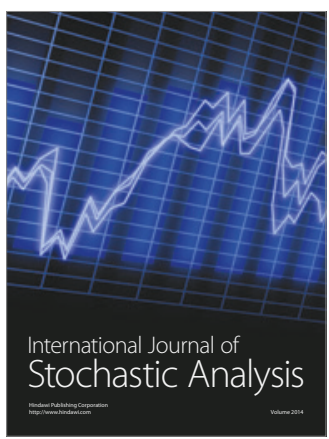

Probability and Statistics
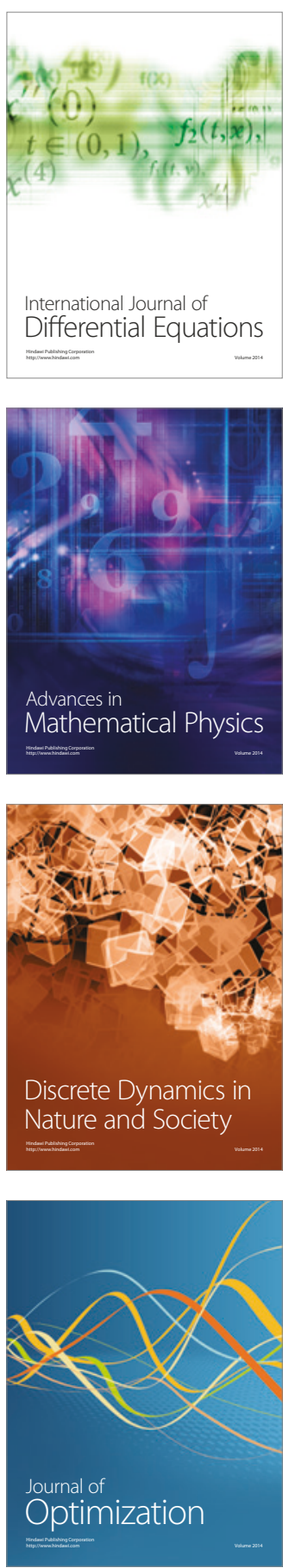